\title{
Fontes de metionina em rações formuladas com base em aminoácidos totais ou digestíveis para frangas de reposição leves e semipesadas
}

\author{
Luiz Gustavo Rombola ${ }^{1}$, Douglas Emygdio de Faria ${ }^{2}$, Bruno José Deponti ${ }^{1}$, Flávio Henrique \\ Araujo Silva ${ }^{1}$, Daniel Emygdio de Faria Filho ${ }^{3}$, Otto Mack Junqueira ${ }^{4}$
}

\footnotetext{
1 Pós-Graduação em Zootecnia - FZEA/USP/Pirassununga - SP.

2 Departamento de Zootecnia - FZEA/USP/Pirassununga - SP.

3 Pós-Graduação em Zootecnia - FCAV/Unesp/Jaboticabal - SP.

${ }^{4}$ Departamento de Zootecnia - FCAV/Unesp/Jaboticabal - SP.
}

RESUMO - Foram conduzidos dois experimentos com o objetivo de avaliar a utilização de duas fontes de metionina (em pó ou líquida) em rações formuladas com base em aminoácidos digestíveis ou totais para frangas de reposição leves e semipesadas, nas fases inicial (de 1 a 6 semanas de idade) e de crescimento (de 11 a 16 semanas de idade). Em cada experimento, foram utilizadas 384 aves distribuídas em delineamento inteiramente ao acaso, em esquema fatorial $2 \times 2 \times 2$, composto de duas linhagens (Hy-Line W36 e Hy-Line Brown), duas fontes de metionina (HMTBA - 88\% e DL-Metionina - 99\%) e dois critérios de formulação da dieta (aminoácidos totais e digestíveis), totalizando oito tratamentos, cada um com seis repetições de oito aves. Foram avaliados os consumos de ração, proteína bruta e energia metabolizável, o peso e ganho de peso corporal e a conversão alimentar das aves. Não houve interação entre os fatores para nenhuma das variáveis estudadas. As aves da linhagem Brown apresentaram maior consumo de ração, peso corporal e ganho de peso. As fontes de metionina e os critérios de formulação de ração não influenciaram as características de desempenho. As aves das linhagens W36 e Brown da linhagem Hy-Line apresentam diferentes perfis de desenvolvimento corporal. A metionina em pó (DL-metionina - 99\%) ou a líquida (HMTBA - 88\%), assim como os critérios de formulação de ração (aminoácidos totais ou digestíveis) proporcionam desempenho semelhante em aves de reposição.

Palavras-chave: aves, crescimento, cria, critérios de formulação, ingrediente

\section{Methionine sources in diets based on total and digestible amino acids for white and brown growing pullets}

\begin{abstract}
Two experiments were carried out to evaluate the use of two methionine sources (powder or liquid) in diets based on total and digestible amino acids for white and brown growing pullets at starter phase (1 to 6 weeks old) and grower phase (11 to 16 weeks old). In each experiment, 384 birds were distributed to a completely randomized design in a $2 \times 2 \times 2$ factoria arrangement, composed of bird strain (Hy-Line W36 and Hy-Line Brown), source of methionine (HMTBA - 88\% and DL-methionine - 99\%) and criteria for diet formulation (total and digestible amino acids), totaling eight diets, each with six replications of eight birds each. The characteristics evaluated were: Feed intake and intakes of crude protein and metabolizable energy; body weight and average daily gain and feed conversion ratio of the birds. There was no interaction among the factors for any of the traits. Brown pullets strain showed higher feed intake, body weight and average daily gain. Methionine sources and the criteria for diet formulation did not influence the performance characteristics. Hy-Line W36 and Hy-Line Brown pullets showed different body development profile. Powder methionine (DL-methionine - 99\%) or liquid (HMTBA - 88\%) as well as the criteria for diet formulation (total or digestible amino acids) provide similar performance for growing pullets.
\end{abstract}

Key Words: diet formulation criteria, grower phase, ingredient, poultry, starter phase

\section{Introdução}

O teor de proteína da ração influencia a produtividade e a lucratividade da atividade avícola, portanto, é importante o fornecimento de proteínas e aminoácidos em quantidade e qualidade adequadas para o bom desenvolvi- mento das aves. Neste contexto, a formulação de ração com base na composição em aminoácidos digestíveis contribui para maior precisão no fornecimento de aminoácidos, uma vez que permite considerar a capacidade da ave em aproveitar os aminoácidos dos alimentos e superar eventuais diferenças na digestibilidade dos ingredientes. De acordo 
com Emmert \& Baker (1997), mesmo em rações à base de milho e farelo de soja, é conveniente considerar a composição em aminoácidos digestíveis, sobretudo quando utilizados aminoácidos sintéticos, que são $100 \%$ digestíveis, enquanto a digestibilidade média dos aminoácidos provenientes do milho e do farelo de soja é de aproximadamente $89 \%$. A efetividade da formulação de rações pelo conceito de aminoácidos digestíveis foi comprovada para frangos de corte (Rostagno et al., 1995; Wang \& Parsons, 1998; Douglas \& Parsons, 1999; Araújo et al., 2006; Gomes et al., 2004; Maiorka et al., 2004), no entanto, para poedeiras comerciais em fase de postura, os resultados ainda são controversos (Silva et al., 2000; Casartelli et al., 2004). Para as fases inicial e de crescimento, não foram encontrados relatos científicos.

A metionina é o primeiro aminoácido limitante para aves e, por isso, precisa ser suplementada na sua forma sintética para assegurar boa produtividade do plantel. As fontes sintéticas de metionina podem ser a líquida (HMTBA e DLM-Na) ou em pó (DLM e HMTBA-Ca), segundo Leeson \& Summers (1997). Essas fontes sintéticas de metionina apresentam quantidades iguais dos isômeros D e L, portanto, devem ser convertidas a L-metionina para serem utilizadas na síntese de proteína ou no metabolismo intermediário (Dibner, 2003; Barbi et al., 2004). Muitos estudos têm sido conduzidos para determinação da bioequivalência entre as fontes de metionina para aves (Lemme et al., 2002; Hoehler \& Hooge, 2003; Alvarez et al., 2004; Liu et al., 2004; Yi et al., 2004; Zavala Jr. et al., 2004). De acordo com os fabricantes desses produtos, a metionina líquida (HMTBA) tem concentração molar de $88 \%$ e a metionina em pó (DLM), de 99\%.

A produtividade das aves de postura tem aumentado ao longo dos anos em virtude do constante melhoramento genético dessas aves. A maior parte dos estudos sobre exigências nutricionais para poedeiras comerciais foi realizada com poedeiras leves, no entanto, sabe-se que ambas as variedades diferem quanto às exigências de aminoácidos, o que torna importante a utilização de variedades brancas e marrons nos estudos de nutrição.

Objetivou-se neste trabalho avaliar os efeitos da formulação de rações com base em aminoácidos totais ou digestíveis e de diferentes fonte de metionina sobre o desempenho de frangas leves e semipesadas nas fases inicial e de crescimento.

\section{Material e Métodos}

O experimento 1 foi realizado na fase inicial ( 1 a 6 semanas de idade) e o experimento 2 na fase de crescimento (11 a 16 semanas idade). Em cada experimento, foram utilizadas 384 aves, distribuídas em delineamento inteiramente ao acaso em esquema fatorial $2 \times 2 \times 2$, composto de dois critérios de formulação (aminoácidos totais e aminoácidos digestíveis), duas fontes de metionina (metionina líquida, HMTBA - 88\%; ou metionina em pó, DLM - 99\%) e duas linhagens (Hy-Line W36 e Hy-Line Brown), totalizando oito tratamentos, cada um com seis repetições de oito aves.

Os ingredientes utilizados nas rações experimentais foram analisados quanto ao perfil de aminoácidos pela Novus Int. ${ }^{\circledR}$ (Tabela 1), considerando a composição dos demais nutrientes e os níveis nutricionais decritos por Rostagno et al. (2000). Como coeficientes de digestibilidade dos aminoácidos dos ingredientes utilizados neste estudo foram considerados os valores reportados por Rostagno et al. (2000) e obtidos em análises laboratoriais realizadas pela Novus Int. ${ }^{\circledR}$. Os níveis de suplementação de DLM e HMTBA para as fases inicial e de crescimento (Tabelas 2 e 3) foram baseados no conteúdo de metionina encontrado no produto comercial, de 99 e $88 \%$, respectivamente.

$\mathrm{Na}$ fase inicial, as aves foram alojadas em baterias de arame galvanizado dispostas em andares, providas de comedouros e bebedouros tipo calha metálica. $\mathrm{Na}$ fase de

Tabela 1 - Composição em proteína e aminoácidos dos ingredientes das rações experimentais (na matéria natural)

\begin{tabular}{|c|c|c|c|c|c|}
\hline Proteína e aminoácidos (\%) & $\begin{array}{l}\text { Milho } \\
\text { grão }\end{array}$ & $\begin{array}{l}\text { Farelo } \\
\text { de soja }\end{array}$ & $\begin{array}{l}\text { Farelo } \\
\text { de trigo }\end{array}$ & $\begin{array}{c}\text { Farinha de } \\
\text { carne e ossos (45\%) }\end{array}$ & $\begin{array}{c}\text { Farinha de } \\
\text { vísceras de aves }\end{array}$ \\
\hline Matéria seca & 89,1 & 86,8 & 88,1 & 93,4 & 90,9 \\
\hline Metionina & 0,18 & 0,59 & 0,25 & 0,58 & 0,55 \\
\hline Metionina+cistina & 0,40 & 1,21 & 0,60 & 0,90 & 2,71 \\
\hline Lisina & 0,32 & 2,76 & 0,64 & 2,12 & 1,82 \\
\hline Treonina & 0,29 & 1,36 & 0,44 & 1,23 & 2,06 \\
\hline Metionina+cistina & 90,0 & 88,4 & 73,3 & 77,8 & 71,6 \\
\hline Lisina & 81,3 & 90,9 & 76,6 & 82,1 & 78,6 \\
\hline Treonina & 82,8 & 88,2 & 72,7 & 78,9 & 75,7 \\
\hline
\end{tabular}

Valores fornecidos pela Novus $\operatorname{Int}^{\circledR}$. 
Tabela 2 - Rações experimentais fornecidas na fase inicial (1 a 6 semanas)

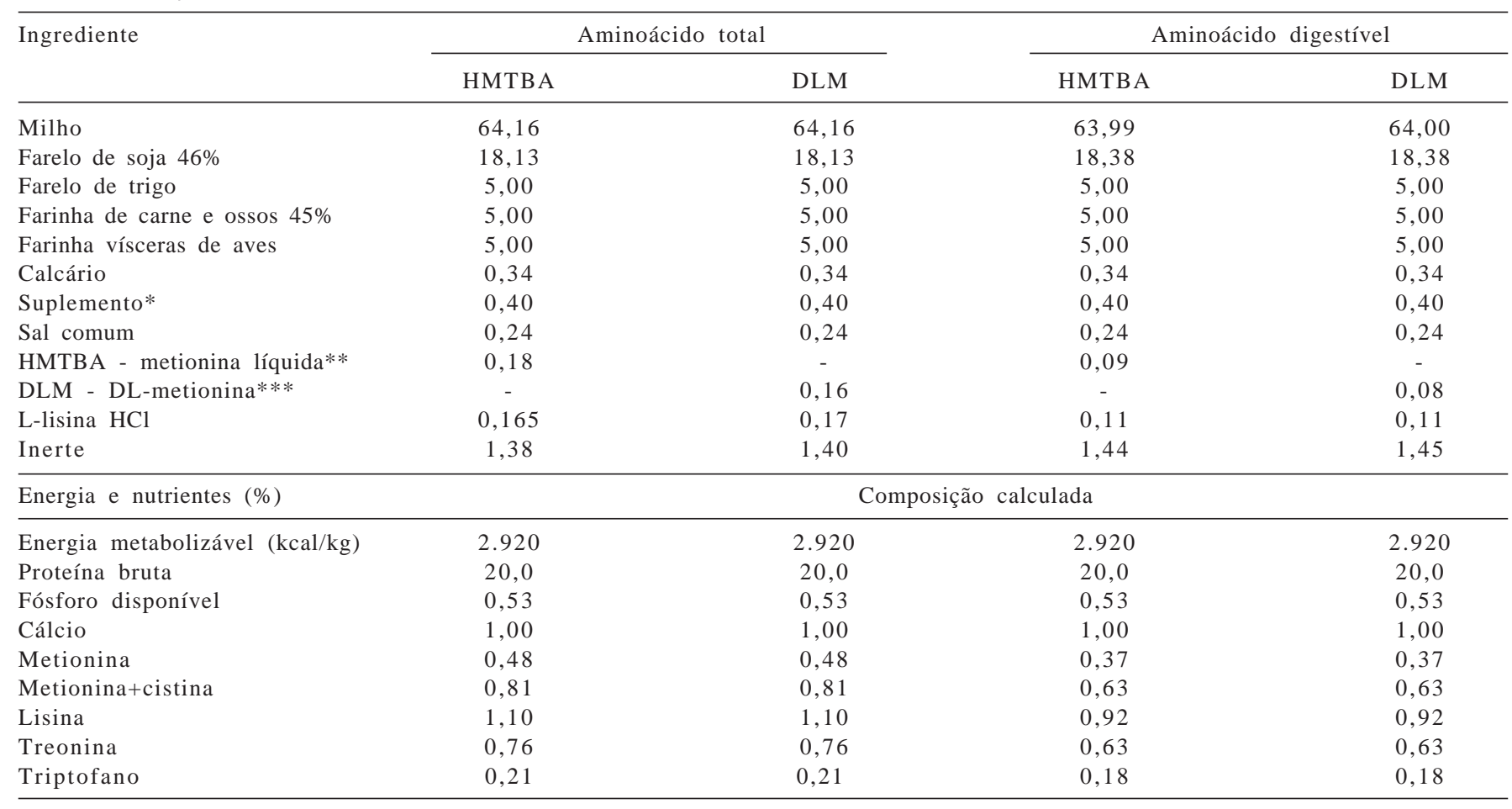

* Vitaminas, minerais e aditivos por kg de ração: vit. A - $7.600 \mathrm{UI}$; vit. D3 - $1.600 \mathrm{UI}$; vit. E - 13,3 mg; vit. K - 1,08 mg; vit. B2 - 4 mg; vit. B12 -10,68 mg; niacina - 26,7 mg; colina - 300 mg; pantotenato de cálcio - 11,4 mg; Se - 0,16 mg; Fe - 67,2 mg; Cu - 8 mg; Mn - 57,2 mg; Co - 0,11 mg; - 0,52 mg; Zn - 64,9 mg; coccidiostático - $1 \mathrm{~g}$; promotor de crescimento - $50 \mathrm{mg}$; antioxidante - $2 \mathrm{mg}$.

** HMTBA é um produto comercial com $88 \%$ de metionina

***DLM é um produto comercial com $99 \%$ de metionina.

Tabela 3 - Rações experimentais fornecidas na fase de crescimento (11 a 16 semanas)

\begin{tabular}{|c|c|c|c|c|}
\hline Ingrediente & \multicolumn{2}{|c|}{ Aminoácido total } & \multicolumn{2}{|c|}{ Aminoácido digestível } \\
\hline Milho & 76,75 & 76,76 & 76,96 & 76,96 \\
\hline Farelo de trigo & 4,50 & 4,50 & 4,50 & 4,50 \\
\hline Farinha de carne e ossos $45 \%$ & 4,50 & 4,50 & 4,50 & 4,50 \\
\hline Farinha vísceras de aves & 4,50 & 4,50 & 4,50 & 4,50 \\
\hline Suplemento* & 0,34 & 0,34 & 0,34 & 0,34 \\
\hline Sal comum & 0,24 & 0,24 & 0,25 & 0,25 \\
\hline HMTBA - metionina líquida** & 0,20 & - & 0,20 & - \\
\hline DLM - DL-metionina*** & - & 0,18 & - & 0,18 \\
\hline L-lisina $\mathrm{HCl}$ & 0,30 & 0,30 & 0,43 & 0,43 \\
\hline Inerte & 1,15 & 1,17 & 1,12 & 1,14 \\
\hline Fósforo disponível & 0,48 & 0,48 & 0,48 & 0,48 \\
\hline Cálcio & 1,00 & 1,00 & 1,00 & 1,00 \\
\hline Metionina & 0,42 & 0,42 & 0,38 & 0,38 \\
\hline Metionina+cistina & 0,76 & 0,76 & 0,62 & 0,62 \\
\hline Lisina & 0,88 & 0,88 & 0,79 & 0,79 \\
\hline Treonina & 0,48 & 0,48 & 0,43 & 0,43 \\
\hline Triptofano & 0,14 & 0,14 & 0,12 & 0,12 \\
\hline
\end{tabular}

* Vitaminas, minerais e aditivos por kg de ração: vit. A - 7.600 UI; vit. D3 - 1.600 Ul; vit. E - 13,3 mg; vti. K - 1,08 mg; vit. B2 - 4 mg; vti. B12 - 10,68 mg; niacina - 26,7 mg; colina - $300 \mathrm{mg}$; pantotenato de cálcio - 11,4 mg; Se - 0,16 mg; Fe - 67,2 mg; Cu - 8 mg; Mn - 57,2 mg; Co - 0,11 mg; I - 0,52 mg; Zn - 64,9 mg; coccidiostático - $1 \mathrm{~g}$; promotor de crescimento - $50 \mathrm{mg}$; antioxidante - $2 \mathrm{mg}$.

** HMTBA é um produto comercial com $88 \%$ de metionina.

***DLM é um produto comercial com $99 \%$ de metionina. 
crescimento, as mesmas aves, após seleção pelo peso médio, foram alojadas em gaiolas de arame dispostas em linhas com comedouros tipo calha e bebedouros com copinho de altura regulável. Em ambas as fases, a água e a ração foram fornecidas à vontade e as aves foram manejadas convencionalmente. Na fase inicial, o programa de iluminação foi de 24 horas de luz por dia e, na de crescimento, de 14 horas de luz por dia.

Foram avaliados os consumos de ração (g), proteína bruta (g) e energia metabolizável (kcal), o peso corporal (g), o ganho de peso corporal (g) e a conversão alimentar (g/g) nas fases inicial ( 1 a 6 semanas de idade) e de crescimento (11 a 16 semanas de idade).

Os dados foram submetidos à análise de variância e, em caso de diferença significativa, as médias foram comparadas pelo teste de Tukey a 5\% de probabilidade. Todas as análises foram realizadas pelo programa Statistical Analysis System $\left(\right.$ SAS $^{\circledR}$ ) (Littell et al., 2002).

\section{Resultados e Discussão}

Não houve interação entre os fatores linhagem, fonte de metionina e critério de formulação de ração nem influência desses fatores sobre os consumos de ração, proteína e energia metabolizável, o peso corporal, o ganho de peso e a conversão alimentar nas fases inicial e de crescimento (Tabela 4).

Considerando os efeitos principais da linhagem de poedeiras, verificou-se que as aves da variedade Hy-Line Brown, tanto na fase inicial como na de crescimento, apresentaram maiores consumos de ração, de proteína bruta e de energia metabolizável, além de maior peso e ganho de peso corporal. Os resultados obtidos neste estudo diferem de relatos de Vargas Júnior et al. (2003) de que aves leves apresentaram maior consumo de ração em comparação a aves semipesadass. Durante a fase inicial, as aves da variedade Hy-Line Brown apresentaram melhor conversão alimentar, mas, durante a fase de crescimento, as aves Hy-Line W36 superaram quanto à conversão alimentar.

As fontes de metionina estudadas não influenciaram as características de desempenho das aves, tanto na fase inicial como na de crescimento. Harms \& Russell (1994), comparando a eficiência relativa da DLM e da HMTBA em poedeiras comerciais, não observaram diferenças na eficiência relativa entre as fontes quando compararam a quantidade de metionina necessária para produzir $1 \mathrm{~g}$ de ovo. Esses autores concluíram que, em base molar, a DLM e a HMTBA possuem a mesma eficiência em poedeiras na fase de produção. Liu et al. (2004) estimaram a bioequivalência da HMTBA e DLM, na base molar, em poedeiras e não observaram diferenças no consumo de ração entre as fontes de metionina e concluíram ainda que a bioequivalência média da HMTBA em relação à DLM é de $89,2 \%$ para produção de ovos, $88,8 \%$ para massa de ovos e $85,7 \%$ para peso de ovos. Não foram encontrados trabalhos na literatura sobre fontes de metionina e desempenho de poedeiras comerciais nas fases inicial e de crescimento. Em frangos de corte, Yi et al. (2004) encontraram peso corporal semelhante quando utilizaram HMTBA (88\%) e DLM (99\%). Do mesmo modo, Zavala Jr. et al. (2004) obtiveram resultados de

Tabela 4 - Desempenho de frangas de reposição leves e semipesadas nas fases inicial e de crescimento alimentadas com rações formuladas com metionina líquida ou em pó, com base nos conceitos de aminoácidos totais ou digestíveis

\begin{tabular}{|c|c|c|c|c|c|c|c|}
\hline \multirow[t]{2}{*}{ Característica } & \multicolumn{2}{|c|}{ Linhagem } & \multicolumn{2}{|c|}{ Fonte de metionina* } & \multicolumn{2}{|c|}{ Critério de formulação da ração } & \multirow{2}{*}{ CV (\%) } \\
\hline & W36 & Brown & НМТВА & DLM & Aminoácidos totais & Aminoácidos digestíveis & \\
\hline \multicolumn{8}{|l|}{ Fase inicial } \\
\hline Consumo de ração (g) & $874 b$ & $998 \mathrm{a}$ & 938 & 933 & 948 & 924 & 4,73 \\
\hline Consumo de proteína bruta (g) & $174 b$ & $200 \mathrm{a}$ & 188 & 186 & 190 & 185 & 4,73 \\
\hline $\begin{array}{l}\text { Consumo de energia } \\
\text { metabolizável (Mcal) }\end{array}$ & $2,53 b$ & $2,90 \mathrm{a}$ & 2,73 & 2,71 & 2,75 & 2,68 & 4,79 \\
\hline Conversão alimentar & $2,33 a$ & $2,15 b$ & 2,25 & 2,25 & 2,22 & 2,26 & 5,01 \\
\hline \multicolumn{8}{|l|}{ Fase de crescimento } \\
\hline Consumo de ração (g) & $2.436 b$ & $2.788 a$ & 2.608 & 2.616 & 2.612 & 2.612 & 3,57 \\
\hline Consumo de proteína bruta (g) & $390 \mathrm{~b}$ & $448 a$ & 417 & 418 & 418 & 418 & 3,57 \\
\hline
\end{tabular}

Médias seguidas de letras diferentes na mesma linha, diferem $(P<0,05)$ entre si pelo teste Tukey.

* HMTBA - metionina líquida = produto comercial com $88 \%$ de metionina; DLM - metionina em pó = produto comercial com $99 \%$ de metionina. 
desempenho semelhantes em frangos de corte quando utilizaram as duas fontes de metionina, mas com relação equimolar diferente, considerando HMTBA com $65 \%$ de metionina e DLM com 99\%.

Os critérios de formulação não influenciaram as características de desempenho nas fases inicial e de crescimento, exceto o peso corporal na fase inicial, que foi maior nas aves alimentadas com as rações formuladas pelo conceito de aminoácidos totais. Ressalta-se que as rações foram compostas de cinco ingredientes diferentes quanto à digestibilidade dos aminoácidos. Provavelmente, o nível dos ingredientes influenciou os resultados. Casartelli et al. (2004), utilizando rações formuladas pelos conceitos de aminoácidos totais e digestíveis, observaram que as formulações com aminoácidos totais promoveram melhores resultados de consumo de ração, produção de ovos, conversão alimentar e gravidade específica do ovo. Na pesquisa realizada por esses autores, o pior desempenho obtido com as rações formuladas com base em aminoácidos digestíveis pode estar relacionado ao seu menor nível de proteína (12,5\% PB comparado com 14,5\% PB da ração formulada com aminoácidos totais), que pode ter ocasionado deficiência de nitrogênio, comprometendo a síntese de aminoácidos não essenciais.

O peso corporal das aves da linhagem Hy-Line W36 a partir da terceira semana foi ligeiramente inferior ao recomendado no manual da linhagem (Hy-Line W36, 2003-2005), enquanto o das aves Hy-Line Brown foi ligeiramente superior (Tabela 5) durante praticamente todo o período experimental, com exceção da $1^{\underline{a}}$ e a $16^{\underline{a}}$ semanas, quando

Tabela 5 - Peso corporal (g) observado e sugerido pelo manual de manejo

\begin{tabular}{|c|c|c|c|c|}
\hline \multirow[t]{2}{*}{ Semana } & Hy-Line & W36 & Hy-Line & Brown \\
\hline & Manual* & Observado & Manual* & Observado \\
\hline
\end{tabular}

Fase inicial

\begin{tabular}{ccccc}
1 & 65 & 66 & 70 & 66 \\
2 & 110 & 112 & 115 & 121 \\
3 & 185 & 176 & 190 & 202 \\
4 & 260 & 240 & 280 & 287 \\
5 & 340 & 321 & 380 & 387 \\
6 & 425 & 411 & 480 & 496 \\
\hline \multicolumn{5}{c}{ Fase de crescimento } \\
11 & 895 & 851 & 960 & 1.040 \\
12 & 985 & 933 & 1.050 & 1.161 \\
13 & 1.065 & 999 & 1.130 & 1.213 \\
14 & 1.135 & 1.055 & 1.210 & 1.259 \\
15 & 1.190 & 1.114 & 1.290 & 1.308 \\
16 & 1.240 & 1.179 & 1.430 & 1.384 \\
\hline
\end{tabular}

* Adaptado dos manuais de manejo: Hy-Line variety W36 (2003 - 2005) e Hy-Line variety Brown (2002 - 2004). o peso corporal ficou abaixo do recomendado (Hy-Line Brown, 2002-2004).

\section{Conclusões}

A metionina em pó (DLM - 99\%) ou líquida (HMTBA 88\%), assim como os critérios de formulação de ração (aminoácidos totais ou digestíveis), promove desempenho semelhante em aves de reposição.

\section{Literatura Citada}

ALVAREZ M.; LOCATELli, M.L.; PEREZ, G. et al. [2004]. Comparison of methionine sources in laying hens under commercial conditons in México. Disponível em: <http;// www.poultryscience.org/spss2004/abstracts.pdf > Acesso em: $18 / 2 / 2005$

ARAÚJO, L.F.; JUNQUEIRA, O.M.; ARAÚJO, C.S.S. et al. Different criteria for feed formulation base don digestible amino acids for broilers. Brazilian Journal of Poultry Science, v.8, p.201205, 2006.

BARBI, J.H.T.; DIBNER, J.; PEAK, S. Mais que uma fonte de metionina. Revista Ave World, v.11, p.36-41, 2004.

DIBNER, J.J. Review of the metabolism of 2-hydroxy-4(methylthio) butanoic acid. World's Poultry Science Journal, v.59, p.99-110, 2003.

CASARTELLI, E.M.; JUNQUEIRA, O.M.; FILARDI, R.S. et al. Formulações de rações para poedeiras comerciais utilizando-se diferentes recomendações de aminoácidos totais e digestíveis. Revista Brasileira de Ciência Avícola, v.6, p.25, 2004 (supl.).

DOUGLAS, M.W.; PARSONS, C.M. Dietary formulation with rendered spent hen meals on a total amino acids versus a digestible amino acid basis. Poultry Science, v.78, p.556-560, 1999.

EMMERT, J.L.; BAKER, D.H. Use of the ideal protein concept for precision formulation of amino acid levels in broilers diets. Journal of Applied Poultry Research, v.6, p.462-470, 1997.

GOMES, G.A.; ARAÚJO, L.F.; JUNQUEIRA, O.M. et al. Dietas formuladas com aminoácidos totais e digestíveis para frangos de corte na fase de crescimento. Revista Brasileira de Ciência Avícola, v.6, p.39, 2004 (supl.).

HARMS, R.H.; RUSSELL, G.B. A comparison of the bioavailability of DL-methionine and methionine hydroxy analogue acid for the commercial laying hen. Journal of Applied Poultry Research, v.3, p.1-6, 1994.

HOEHLER, D.; HOOGE, D.M. Relative effectiveness of methionine sources in turkeys - scientific and new commercial data. International Journal of Poultry Science, v.2, p.361-366, 2003

HY-LINE [2002-2004]. Variety Brown Guia de manejo (20022004). Disponível em: <http://www.hylinedobrasil.com.br> Acesso em: 2/3/2005.

HY-LINE. [2003-2005]. Variety W36. Guia de manejo (20032005). Disponível em: <http://www.hylinedobrasil.com.br> Acesso em: 2/3/2005.

LEESON, S.; SUMMERS, D.J. Commercial poultry nutrition. 2.ed. Guelph: University Books, 1997. 370p.

LEMME, A.; HOEHLER, D.; BRENNAN, J.J. et al. Relative effectiveness of methionine hydroxy analog compared to DL-methionine in broiler chickens. Poultry Science, v.81, p.838-845, 2002.

LITTELL, R.C.; STROUP, W.W.; FREUND, R.J. SAS for linear models. 4.ed. Cary: SAS Institute, 2002. (CD-ROM). 
LIU, Z.; BATEMAN, A.; BRYANT, M. et al. Estimation of bioavailability of DL-methionine hidroxy analogue relative to DL-methionine in layers with exponential and slope-ratio models. Poultry Science, v.83, p.1580-1586, 2004.

MAIORKA, A.; DAHLKE, F.; SANTIN, E. et al. Effect of energy levels of diets formulated on total or digestible amino acids basis on broiler performance. Brazilian Journal of Poultry Science, v.6, n.2, p.87-91, 2004.

ROSTAGNO, H.S.; PUPA, J.M.R.; PACK, M. Diet formulation for broilers based on total versus digestible amino acids. Journal of Applied Poultry Research, v.4, p.293-299, 1995.

ROSTAGNO, H.S.; ALBINO, L.F.T.; DONZELE, J.L. et al. Tabelas brasileiras para aves e suínos: composição de alimentos e exigências nutricionais. Viçosa, MG: Editora UFV, 2000. 124p.

SILVA, J.H.V.; MUKAMI, F.; ALBINO, L.F.T. Uso de rações à base de aminoácidos digestíveis para poedeiras. Revista Brasileira de Zootecnia, v.29, p.1446-1451, 2000.
VARGAS JR., J.G.; ALBINO, L.F.T.; ROSTAGNO, H.S. et al. Níveis nutricionais de cálcio e fósforo disponíveis para aves de reposição leves e semipesadas de 0 a 6 semanas de idade. Revista Brasileira de Zootecnia, v.32, n.6, p.1919-1926, 2003.

YI, G.F.; VÁZQUEZ-AÑÓN, M.; HAMPTON, T. et al. [2004]. Comparison of 2-hydroxy-4 (methylthio) butanoic acid (HMTBA) and DL-Methionine (DLM) bioefficacy in broilers fed diets marginally deficient in total súlfur amino acids (TSAA) under practical field conditions. Disponível em: <http://www.poultryscience.org/spss2004/ abstracts. pdf> Acesso em: 18/2/2005.

WANG, X.; PARSONS, C.M. Dietary formulation with meat and bone meal on a total versus a digestible or bioavailable amino acid basis. Poultry Science, v.77, p.1010-1015, 1998.

ZAVALA JR., G.; LOCATELLI, M.L.; PEREZ, G. et al. [2004]. Comparing methionine sources using commercial broiler diets in central México. Disponível em: <http://www.poultry science.org/spss2004/ abstracts.pdf> Acesso em: 18/2/2005. 